\title{
Clinical features of snoring patients during sedative endoscopy
}

Jung Wha Chung ${ }^{1}$, Nayoung Kim ${ }^{1,2}$, Jee Hye Wee ${ }^{3}$, Jaebong Lee ${ }^{4}$, Jongchan Lee ${ }^{1}$, Soohoon Kwon ${ }^{1}$, Young-Jae Hwang ${ }^{1}$, Hyuk Yoon ${ }^{1}$, Cheol Min Shin ${ }^{1}$, Young Soo Park ${ }^{1,2}$, Dong Ho Lee ${ }^{1,2}$, and Jin-Wook Kim²,

\begin{abstract}
${ }^{1}$ Department of Internal Medicine, Seoul National University Bundang Hospital, Seongnam; ${ }^{2}$ Department of Internal Medicine, Seoul National University College of Medicine, Seoul; ${ }^{3}$ Department of Otorhinolaryngology, ${ }^{4}$ Medical Research Collaborating Center, Seoul National University Bundang Hospital, Seongnam, Korea
\end{abstract}

Received: March 29, 2017

Revised : July 29, 2017

Accepted: August 2, 2017

\section{Correspondence to}

Nayoung Kim, M.D.

Department of Medicine, Seoul National University Bundang Hospital, 82 Gumi-ro 173beongil, Bundang-gu, Seongnam 13620, Korea

Tel: +82-31-787-7009

Fax: 82-31-787-4051

E-mail: nakim@snubh.org

Jin-Wook Kim, M.D.

Department of Medicine, Seoul National University Bundang Hospital, 82 Gumi-ro 173beongil, Bundang-gu, Seongnam 13620 , Korea

Tel: +82-31-787-7009

Fax: +82-31-787-4051

E-mail:kimjw@snubh.org
Background/Aims: Snoring is the sound of turbulence and vibration of the upper respiratory tissues and has been identified as a risk factor of obstructive sleep apnea (OSA) and cardiovascular disease. The aim of this study was to identify associated clinical factors in snoring patients undergoing sedative endoscopy.

Methods: A total of 49 patients who snored during standard sedative endoscopy and 127 controls were prospectively enrolled from June 2015 to June 2016. The Korean version of the Berlin Questionnaire was used to identify risk factors of OSA. Clinical information, including comorbidities, was collected from electronic medical records.

Results: The snoring group showed a higher risk of OSA $(42.9 \%$ vs. $26.8 \%, p=$ 0.039 ), and a higher prevalence of coronary artery disease ( $10.2 \%$ vs. $0.8 \%, p=0.007$ ) and advanced gastric cancer $(12.2 \%$ vs. $2.4 \%, p=0.015)$ compared with the control group. Multivariate analysis showed that coronary artery disease (odds ratio [OR], 13.93; 95\% confidence interval [CI], 1.24 to $155.90 ; p=0.033$ ) and advanced gastric cancer (OR, 5.21; 95\% CI, 1.01 to 26.98; $p=0.049$ ) were significantly associated with snoring. However, a history of gastrectomy showed only a marginally significant association with snoring (OR, 2.16; 95\% CI, 0.91 to $5.11 ; p=0.079$ ).

Conclusions: Patients who snore during sedative endoscopy may need to be evaluated for possible coronary artery disease.

Keywords: Snoring; Stomach neoplasms; Coronary artery disease; Sleep apnea, obstructive; Surveys and questionnaires

\section{INTRODUCTION}

Snoring is the sound of turbulence and vibration of the upper respiratory tissues which is caused by complete or partial obstruction of the upper respiratory tract. Snoring during sleep can be a sign or an alarm of ob- structive sleep apnea (OSA), which is defined as episodes of repetitive hypopnea or apnea with desaturation and awakening while sleeping. OSA is known to be associated with increased risks of major systemic illness such as cardiovascular disease [1,2], stroke [2], diabetes [3-5], high blood pressure $[5,6]$, and postoperative cardiovas- 
cular or respiratory complications as well as daytime somnolence, and decreased concentration and quality of life [7]. Although snoring causes significant systemic illness, patients with habitual snoring are sometimes unaware of breathing difficulties even while having repetitive episodes of oxygen desaturation when awake. In the Unites States, a population-based study conducted by The National Sleep Foundation found that $59 \%$ of participants reported snoring. Of the 895 respondents, $54 \%$ reported snoring more than three nights per week and $11 \%$ reported having respiratory pause more than three nights per week. Of the 1,506 respondents, 26\% (31\% of men and $21 \%$ of women) were at high risk for OSA [8]. Another population-based study from India found that $26 \%$ of 2,150 respondents were habitual snorers [9]; among the snorers, $47 \%$ of patients were found to have OSA based-on polysomnography, yielding a prevalence $14 \%$ [9]. Although a high prevalence of snorers and OSA has been reported in previous studies, Young et al. [10] estimated that more than $80 \%$ of OSA patients are not detected in both sexes. The prevalence of patients with habitual snoring is increasing due to the rise in obesity [11]; thus, screening methods are needed to detect individuals at risk for snoring.

Several questionnaires have been developed in order to identify groups at high-risk group for snoring and its associated symptoms. The Berlin Questionnaire (BQ) is one of the most validated tools for identifying patients at risk of OSA. One systematic review reported that the BQ has the highest sensitivity (69\% to $86 \%$ ) and specificity ( $56 \%$ to $95 \%$ ) for predicting the presence of OSA [12]. The BQ is a simple test that has been widely used in previous studies $[8,13,14]$, and it has been translated into multiple languages $[15,16]$. Nevertheless, due to the lack of subjective perception, self-reported questionnaires are regarded as insufficient for screening patients at high-risk of OSA.

Recently, there have been several reports that sedative endoscopy could be used as a screening tool for OSA when snoring is observed during the procedure [17-19]. Sharara et al. [17] observed that 24 out of 131 patients (18.3\%) snored under conscious sedation and 20 patients were later diagnosed with OSA by polysomnography. Another study diagnosed OSA in seven patients out of 10 patients with snoring symptoms among 600 participants who underwent sedative endoscopy [19]. This report suggests that snoring symptoms during a sedative endoscopy could be used as a screening opportunity to identify high-risk patients [19]. Previous studies on snoring in Western populations did not include critical clinical features such as comorbidities. The aim of this study was to evaluate the snoring symptom and to identify associated disorders such as cardiovascular disease in patients from an Eastern population who snore during sedative endoscopy.

\section{METHODS}

\section{Study population}

Patients 18 years or older who underwent sedative endoscopy for either routine esophagogastroduodenoscopy or colonoscopy by specialized gastroenterologist ( $\mathrm{N}$. Kim) at Seoul National University Bundang Hospital between June 2015 and June 2016 were enrolled in this study. Patients were excluded for the following reasons; a history of long-term narcotic use, haloperidol use, or substance abuse; craniofacial deformity or structural abnormality including tumor of the nasopharynx or oropharynx; and oxygen saturation less than 90\% (measured by pulse oximetry) before induction of endoscopic sedation. Sedation was achieved by intravenous injection of midazolam alone or in combination with pethidine per the institution's standard protocol; sedative dosages were determined by the endoscopy specialists according to the patients' age and bodyweight. Patients were observed for snoring symptom for at least 1 minute in the left lateral decubitus position before the start of endoscopy. The snoring group was defined as patients who snored for at least 10 consecutive seconds or longer. The study protocol was approved by the Ethics Committees of Seoul National University Bundang Hospital (B-1508-312-309), and written informed consent was obtained from all participants.

\section{Data collection}

Patients who agreed to participate in this study were interviewed by trained clinical research coordinators using the Korean version of the $\mathrm{BQ}$ and the Korean Alcohol Use Disorders Identification Test (AUDIT-K). The Korean version of the BQ consists of three categories: snoring, wake-time sleepiness or tiredness, and 
the presence of hypertension or obesity determined by high body mass index (BMI) (Supplementary Table 1) [13]. Patients were stratified as being at high risk of OSA if they had two or three positive categories [15]. Scores on each item were calculated based on the original $\mathrm{BQ}$ instructions; however, that the cut-off value of obesity was modified to BMI $\geq 25 \mathrm{~kg} / \mathrm{m}^{2}$, as suggested by the World Health Organization Western Pacific Regional Office for defining obesity in Asian populations [20]. In order to detect alcohol dependency and drinking-related problems, the AUDIT questionnaires developed by the World Health Organization was used (Supplementary Table 2). The AUDIT has been widely used and its validity and reliability have been evaluated by numerous studies [21,22]; the AUDIT-K is properly translated into Korean [23]. The AUDIT-K contains 10 items: three items on alcohol consumption, three items on drinking behavior and dependency, and four items on consequences or problems associated with drinking. Scores for each of the ten questions range from o to 4. Total scores between 10 and 19 for men or between 6 and 9 for women indicate harmful alcohol use and total scores $\geq$ 20 for men or $\geq 10$ for women indicate a possible alcohol dependence disorder as well as harmful alcohol use.

Several physical measurements, including height, body weight, and neck circumference, as well as social demographic variables such as education level and smoking history, were measured and recorded by the two study investigators. Patients were considered smokers if they currently smoke or had smoked more than 100 cigarettes in the past. Endoscopic findings, sedative dosages, and blood oxygen saturation by pulse oximetry were also collected during endoscopy. Clinical information concerning comorbidities was obtained from the electronic medical records of our institution (BESTcare, Seongnam, Korea) including coronary artery disease, chronic renal or pulmonary disease, confirmed OSA, stroke, malignancy, and surgical history. The existence of coronary artery disease was determined by coronary artery angiography results in the patients who reported chest discomfort or pain. The prevalence of Helicobacter pylori infection was calculated as the sum of past and current infection as the Giemsa staining of endoscopic biopsy samples.

\section{Data analysis}

Sample size calculations were performed before beginning the study. To evaluate the prevalence of habitual snoring symptoms and clinical characteristics of snoring patients under sedation endoscopy, a $z$ test was performed based on previous study sample size [17]. Sharara et al. [17] showed that the rate of snoring symptoms among patients undergoing sedative endoscopy was about $20 \%$ and the proportion of high-risk patients was $6 \%$ in the control group and $70 \%$ in the snoring group. Assuming the sensitivity of the $\mathrm{BQ}$ is 0.69 (power 0.95 and $\alpha 0.01$ ) [15], the total required number of participants for this study was 84 ( 67 in the control group, 17 in the snoring group); assuming a $50 \%$ loss in questionnaires the calculated number of participants was estimated to be 168 (G power version 3.1.9.2; http://www.gpower.hhu.de).

In order to compare the patients between groups with or without snoring symptom during sedative endoscopy, categorical variables were compared using the chisquare test or two-tailed Fischer exact test, and continuous variables were compared using the Mann-Whitney test. Univariate and multivariate logistic regression analyses were used to identify the overall and independent clinical factors associated with snoring during sedative endoscopy. A p value less than 0.05 was regarded as statistically significant. All statistical analyses were conducted with the SPSS version 22.o (IBM Co., Armonk, NY, USA).

\section{RESULTS}

\section{Baseline characteristics and prevalence of snoring during sedative endoscopy}

During the study period, 1,133 patients received sedative endoscopy by N. Kim, of which 176 were prospectively enrolled in the study. Under conscious sedation, 49 patients showed snoring symptom with a prevalence of 4.3\%. The remaining 127 patients did not snore during sedative endoscopy. Some patients underwent endoscopy as a follow-up after an endoscopic submucosal dissection or endoscopic mucosal resection for gastric adenoma or early gastric cancer (EGC). Among the 176 patients, 26 (14.8\%) underwent gastrectomy for EGC ( $\mathrm{n}=$ 17) or advanced gastric cancer (AGC, $n=9)$. The mean \pm standard deviation age was $62.1 \pm 10.3$ years with a maleto-female ratio of 2.03:1 (Table 1). The mean BMI of the 
Table 1. Baseline characteristics of total subjects

\begin{tabular}{|c|c|c|c|c|}
\hline Variable & $\begin{array}{l}\text { Total subjects } \\
\qquad(\mathrm{n}=176)\end{array}$ & $\begin{array}{l}\text { Snoring during } \\
\text { endoscopy }(\mathrm{n}=49)\end{array}$ & $\begin{array}{l}\text { No snoring during } \\
\text { endoscopy }(n=127)\end{array}$ & $p$ value \\
\hline Age, yr & $62.1 \pm 10.3$ & $59 \cdot 3 \pm 10.4$ & $63.1 \pm 10.1$ & $0.026^{\mathrm{a}}$ \\
\hline Male sex & $119(67.6)$ & $44(89.8)$ & $75(59.1)$ & $<0.001^{\mathrm{a}}$ \\
\hline Height, cm & $164.7 \pm 8.0$ & $167.8 \pm 7.9$ & $163.5 \pm 7 \cdot 7$ & $0.001^{\mathrm{a}}$ \\
\hline Body weight, kg & $65.5 \pm 12.7$ & $70.1 \pm 15.4$ & $63.8 \pm 11.0$ & $0.003^{\mathrm{a}}$ \\
\hline Neck circumference, $\mathrm{cm}^{\mathrm{b}}$ & $37.6 \pm 3.6$ & $39.2 \pm 4 \cdot 3$ & $37 \cdot 3 \pm 3 \cdot 5$ & $0.049^{\mathrm{a}}$ \\
\hline Obesity (body mass index $\geq 25 \mathrm{~kg} / \mathrm{m}^{2}$ ) & $66(37.5)$ & $23(46.9)$ & $43(33 \cdot 9)$ & 0.108 \\
\hline Habitual snoring symptom $\geq 3 /$ week & $42(23.9)$ & $20(40.8)$ & $22(17 \cdot 3)$ & $0.001^{\mathrm{a}}$ \\
\hline $\begin{array}{l}\text { High risk group of obstructive sleep apnea } \\
\text { on questionnaire }\end{array}$ & $55(31.3)$ & $21(42.9)$ & $34(26.8)$ & $0.039^{\mathrm{a}}$ \\
\hline Risk of alcohol dependence ${ }^{b}$ & $21(11.9)$ & $4(22.0)$ & $17(13 \cdot 5)$ & 0.302 \\
\hline Smoker ${ }^{\mathrm{b}}$ & $64(36.4)$ & $5(27.8)$ & $59(46.8)$ & 0.128 \\
\hline Education ( $\leq$ middle school) & $25(14.2)$ & $2(11.1)$ & $23(19 \cdot 5)$ & 0.526 \\
\hline Prevalence of Helicobacter pylori infection ${ }^{c}$ & $93(57 \cdot 4)$ & $19(51.4)$ & $74(59.2)$ & 0.396 \\
\hline Gastroesophageal reflux disease & $28(15 \cdot 9)$ & $10(20.4)$ & $18(14.2)$ & 0.311 \\
\hline Chronic atrophic gastritis & $84(47 \cdot 7)$ & $16(37.2)$ & $68(55 \cdot 3)$ & $0.041^{\mathrm{a}}$ \\
\hline Hiatal hernia & $7(4 \cdot 0)$ & $2(4 \cdot 7)$ & $5(4 \cdot 1)$ & 1.000 \\
\hline Duodenal ulcer & $13(7 \cdot 4)$ & $1(2.3)$ & $12(9.8)$ & 0.187 \\
\hline History of gastrectomy & $26(14.7)$ & $11(22.4)$ & $15(11.8)$ & 0.075 \\
\hline History of gastric cancer & $58(33.0)$ & $13(26.5)$ & $45(35 \cdot 4)$ & 0.260 \\
\hline Early gastric cancer & $49(27.8)$ & $7(14 \cdot 3)$ & $42(33.1)$ & $0.013^{\mathrm{a}}$ \\
\hline Advanced gastric cancer & $9(5 \cdot 1)$ & $6(12.2)$ & $3(2.4)$ & $0.015^{\mathrm{a}}$ \\
\hline Coronary artery disease & $6(3.4)$ & $5(10.2)$ & $1(0.8)$ & $0.007^{\mathrm{a}}$ \\
\hline Obstructive sleep apnea & $5(2.8)$ & $1(2.0)$ & $4(3.1)$ & 1.000 \\
\hline Fatty liver & $18(10.2)$ & $4(8.2)$ & $14(11.0)$ & 0.575 \\
\hline Hypertension & $66(37.5)$ & $22(44 \cdot 9)$ & $44(34.6)$ & 0.208 \\
\hline Diabetes mellitus & $19(10.8)$ & $7(14 \cdot 3)$ & $12(9.4)$ & 0.354 \\
\hline
\end{tabular}

Values are presented as number \pm SD or number (\%).

${ }^{\text {a }}$ Statistical significance.

${ }^{\mathrm{b}}$ Analyzed for 144 patients due to missing values.

${ }^{\mathrm{c} A n a l y z e d ~ f o r ~} 162$ patients due to missing values.

patients was $24.0 \mathrm{~kg} / \mathrm{m}^{2}$, and $23.9 \%$ reported habitual snoring symptoms more than three times a week. Fifty-five patients (31.3\%) were classified as being at high risk of OSA based on the Korean version of the BQ score and $66(37.5 \%)$ were obese $\left(\mathrm{BMI} \geq 25 \mathrm{~kg} / \mathrm{m}^{2}\right)$.

\section{Factors associated with snoring symptoms during sedative endoscopy}

Of the 176 study participants, the proportion at risk for OSA and the proportion with habitual snoring symptoms were higher in the snoring group (42.9\% vs. $26.8 \%$, $p=0.039)$ (Table 1). Snoring patients were, overwhelmingly, male (male-to-female ratio of 8.8:1) with a significantly greater mean body weight and height. The average BMI was higher in the snoring group $\left(24.8 \mathrm{~kg} / \mathrm{m}^{2}\right)$ than in the control group $\left(23.8 \mathrm{~kg} / \mathrm{m}^{2}\right)$; however, this was not statistically significant $(p=0.080)$. Neck circumference was significantly higher in snoring group (39.2 \pm 4.3 $\mathrm{cm})$ than in the control group $(37.3 \pm 3.5 \mathrm{~cm})(p=0.049)$. There were no significant differences in smoking, alcohol habit, or education level between groups (Table 1). The total prevalence of $H$. pylori infection was $57.4 \%$ and 
there was no difference between the two groups (51.4\% vs. $59.2 \%, p=0.396$ ). The proportion of patients with a history of gastrectomy was higher in the snoring group (22.44\%) than in the control group (11.8\%); however, this was not statistically significant $(p=0.079)$. Patients who snored had a higher prevalence of AGC (12.2\% vs. 2.4\%, $p=0.015)$ and coronary artery disease (10.2\% vs. $0.8 \%, p=$ $0.007)$ than the control group. However, EGC was more common in the control group (33.1\% vs. $14.3 \%, p=0.013$ ). There was no difference between the two groups in the types or dosages of sedatives given. No cardiopulmonary events were reported during endoscopic sedation in any of the study participants.

\section{Factors predicting snoring during sedative endoscopy}

Logistic regression analysis was performed to determine the correlation between snoring symptoms during sedative endoscopy and other clinical features (Table 2). Age was negatively associated with snoring symptoms during sedative endoscopy with significance; analyses with age ranges over 10 years; however, showed no significant difference. Univariate analysis showed that snoring symptoms were positively correlated with male sex, neck circumference, and the number of positive categories on the Korean version of the BQ. Male sex and the number of positive categories on the Korean version of the BQ still showed significance after multivariate analyses. Among clinical characteristics, a history of gastrectomy was marginally associated with snoring based on univariate analysis (odds ratio [OR], 2.16; 95\% confidence interval [CI], o.91 to $5.11 ; p=0.079)$. Histories of AGC (OR, 5.21; 95\% CI, 1.01 to 26.98; $p=0.049$ ) and coronary artery disease (OR, 13.93; 95\% CI, 1.24 to 155.90; $p=0.033)$ were positively correlated with snoring after adjusting for age, sex, and the number of positive categories on the BQ. EGC was negatively associated with snoring in the univariate analysis but only showed marginal significance in the multivariate analysis (OR, o.42; $95 \%$ CI, 0.16 to 1.10; $p=0.077$ ). Other comorbidities such as fatty liver, hypertension, and diabetes mellitus were not correlated with snoring. Midazolam dosage also showed no correlation with snoring (data not shown).

\section{Comparison of participants according to a history of gastrectomy}

Patients whit a history of gastrectomy $(n=26)$ (Table
3) demonstrated a shorter neck circumference $36.1 \mathrm{~cm}$ vs. $37.8 \mathrm{~cm}, p=0.045)$ and lower rates of obesity $(15.4 \%$ vs. $41.3 \%, p=0.01 \angle$, atrophic gastritis (o\% vs. $60.0 \%$, $p<0.001$ ), and harmful alcohol use (o\% vs. $16.9 \%, p=$ 0.045) compared with patients without a history of gastrectomy. While the prevalence of $H$. pylori infection was higher (69.2\%) in patients with a history of gastrectomy, it did not reach statistical significance (69.2\% vs. $55.1 \%$, $p=0.183$ ).

Clinical features of patients were also compared according to a history of gastric cancer (Supplementary Table 3). Among the 176 study participants, nine were diagnosed with AGC and underwent gastrectomy. Patients diagnosed with AGC tended to be older (64.0 years vs. 61.5 years, $p=0.487$ ), and weigh less $(59.7 \mathrm{~kg}$ vs. $66.6 \mathrm{~kg}$, $p=0.005$ ) and none of the AGC patients had fatty liver disease. Among the nine patients with AGC, six showed snoring symptoms during the sedative endoscopy (66.7\% vs. $30.5 \%, p=0.058$ ) and four reported habitual snoring symptoms ( $44.4 \%$ vs. $27.1 \%, p=0.271)$.

\section{Comparison of patients according to the history of coronary artery disease}

Six patients had a history of coronary artery disease, none of whom had a history of gastric cancer (Table 4 ). These patients were generally older men $(65.2$ years vs. 61.9 years, $p=0.452$ ) with greater body weight (69.4 kg vs. $65.4 \mathrm{~kg}, p=0.445$ ). Five of these patients showed snoring symptoms during sedative endoscopy (83.3\% vs. $25.9 \%$, $p=0.007)$ and four patients reported habitual snoring symptoms ( $44.4 \%$ vs. $27.1 \%, p=0.271)$. Of the six patients with coronary artery disease, two (40.0\%) had a history of $\mathrm{H}$. pylori infection, although one was not tested for $H$. pylori; $58.0 \%$ of patients had a history of $H$. pylori infection in the control group $(p=0.652)$. Four of the six patients with coronary artery disease had diabetes mellitus (66.7\% vs. 8.8\%, $p=0.001$ ), three had hypertension and one had fatty liver disease $(p=0.673$ and $p=0.482$, respectively).

\section{DISCUSSION}

This is the first observational study to correlate snoring symptoms during routine gastrointestinal sedative endoscopy with endoscopic findings and comorbidities. 
Table 2. Predicting factors for snoring symptoms during sedative endoscopy

\begin{tabular}{|c|c|c|c|c|c|c|}
\hline \multirow{2}{*}{ Variable } & \multicolumn{3}{|c|}{ Univariate } & \multicolumn{3}{|c|}{ Multivariate } \\
\hline & OR & $95 \% \mathrm{CI}$ & $p$ value & OR & $95 \% \mathrm{CI}$ & $p$ value \\
\hline Mean age, yr & 0.96 & $0.93-0.99$ & 0.028 & 0.96 & $0.92-0.99$ & $0.028^{\mathrm{a}}$ \\
\hline $30-39(n=4)$ & 1.00 & Reference & & & & \\
\hline $40-49(\mathrm{n}=15)$ & 0.08 & $0.01-1.11$ & 0.060 & & & \\
\hline $50-59(\mathrm{n}=53)$ & 0.17 & $0.02-1.77$ & 0.139 & & & \\
\hline $60-69(n=59)$ & 0.11 & $0.01-1.18$ & 0.068 & & & \\
\hline $70-79(n=38)$ & 0.10 & $0.01-1.12$ & 0.062 & & & \\
\hline $80-89(n=7)$ & 0.06 & $0.01-1.23$ & 0.068 & & & \\
\hline \multicolumn{7}{|l|}{ Sex } \\
\hline Female $(\mathrm{n}=57)$ & 1.00 & Reference & & & & \\
\hline Male $(\mathrm{n}=119)$ & 6.10 & $2.27-16.43$ & $<0.001$ & 4.05 & $1.38-11.90$ & $0.011^{\mathrm{a}}$ \\
\hline Neck circumference, $\mathrm{cm}^{\mathrm{b}}$ & 1.16 & $1.00-1.34$ & 0.053 & & & \\
\hline \multicolumn{7}{|l|}{ Body mass index, $\mathrm{kg} / \mathrm{m}^{2}$} \\
\hline$<25$ & 1.00 & Reference & & & & \\
\hline$\geq 25$ & 1.73 & $0.88-3.38$ & 0.110 & & & \\
\hline \multicolumn{7}{|l|}{ No. of positive category on $\mathrm{K}-\mathrm{BQ}^{\mathrm{c}}$} \\
\hline No positive category $(\mathrm{n}=49)$ & 1.00 & Reference & & & & \\
\hline One positive category $(n=70)$ & 5.16 & $1.65-16.13$ & 0.005 & 4.46 & $1.26-15.81$ & $0.021^{\mathrm{a}}$ \\
\hline Two positive categories $(n=48)$ & 6.17 & $1.89-20.11$ & 0.003 & $4 \cdot 37$ & $1.16-16.46$ & $0.029^{\mathrm{a}}$ \\
\hline Three positive categories $(\mathrm{n}=9)$ & 22.50 & $4.02-125.95$ & $<0.001$ & 12.81 & $1.94-84.61$ & $0.008^{2}$ \\
\hline Harmful alcohol use $(n=21)^{b, c}$ & 1.83 & $0.54-6.22$ & 0.332 & & & \\
\hline \multicolumn{7}{|l|}{ Smoking history ${ }^{\mathrm{b}}$} \\
\hline Nonsmoker $(\mathrm{n}=80)$ & 1.00 & Reference & & & & \\
\hline Smoker $(n=64)$ & 2.29 & $0.77-6.80$ & 0.136 & & & \\
\hline Prevalence of Helicobacter pylori infection ${ }^{\mathrm{d}}$ & 0.73 & $0.35^{-1.52}$ & 0.397 & & & \\
\hline Gastroesophageal reflux disease $(n=28)$ & 1.77 & $0.74-4.20$ & 0.197 & & & \\
\hline History of gastrectomy $(n=26)$ & 2.16 & $0.91-5.11$ & 0.079 & & & \\
\hline \multicolumn{7}{|l|}{ History of gastric cancer } \\
\hline No history of gastric cancer $(n=118)$ & 1.00 & Reference & & & & \\
\hline Early gastric cancer $(n=49)$ & 0.38 & $0.16-0.93$ & 0.033 & 0.42 & $0.16-1.10$ & 0.077 \\
\hline Advanced gastric cancer $(\mathrm{n}=9)$ & 4.56 & $1.08-19.23$ & 0.039 & 5.21 & $1.01-26.98$ & $0.049^{\mathrm{a}}$ \\
\hline Coronary artery disease $(n=6)$ & $14 \cdot 32$ & $1.63-125.94$ & 0.016 & 13.93 & $1.24-155.90$ & $0.033^{\mathrm{a}}$ \\
\hline Obstructive sleep apnea $(\mathrm{n}=5)$ & 0.64 & $0.07-5.88$ & 0.694 & & & \\
\hline Fatty liver $(\mathrm{n}=18)$ & 0.72 & $0.22-2.30$ & 0.576 & & & \\
\hline Hypertension $(n=66)$ & 1.54 & $0.79-3.01$ & 0.209 & & & \\
\hline Diabetes mellitus $(\mathrm{n}=19)$ & 1.60 & $0.59-4.33$ & 0.357 & & & \\
\hline
\end{tabular}

OR, odds ratio; CI, confidence interval; K-BQ, the Korean version of the Berlin Questionnaire.

${ }^{a}$ Statistical significance.

${ }^{\mathrm{b}}$ Analyzed for 144 patients due to missing values.

${ }^{\mathrm{c}}$ Analyzed by calculation of scores using the questionnaires (the Korean version of the Berlin Questionnaire and the Alcohol Use Disorders Identification Test).

dAnalyzed for 162 patients due to missing values. 
Table 3. Comparison of clinical features of patients according to the history of gastrectomy

\begin{tabular}{|c|c|c|c|}
\hline Variable & No history of gastrectomy $(\mathrm{n}=150)$ & History of gastrectomy $(n=26)$ & $p$ value \\
\hline Age, $\mathrm{yr}^{\mathrm{a}}$ & $61.8 \pm 10.3$ & $63.4 \pm 10.0$ & 0.463 \\
\hline Male sex & $99(66.0)$ & $20(76.9)$ & 0.272 \\
\hline Neck circumference, $\mathrm{cm}^{\mathrm{a}, \mathrm{b}}$ & $37.8 \pm 3.6$ & $36.1 \pm 3.3$ & $0.045^{\mathrm{c}}$ \\
\hline Obesity (body mass index $\geq 25 \mathrm{~kg} / \mathrm{m}^{2}$ ) & $62(41.3)$ & $4(15 \cdot 4)$ & $0.012^{c}$ \\
\hline Habitual snoring symptom $\geq 3 /$ week & $37(24 \cdot 7)$ & $5(19.4)$ & 0.548 \\
\hline Snoring during sedative endoscopy & $38(25 \cdot 3)$ & $11(42.3)$ & 0.075 \\
\hline High risk group of obstructive sleep apnea & $50(33 \cdot 3)$ & $5(19.2)$ & 0.152 \\
\hline Gastroesophageal reflux disease ${ }^{d}$ & $15(10.7)$ & $1(3.8)$ & 0.471 \\
\hline Chronic atrophic gastritis on endoscopy ${ }^{\mathrm{d}}$ & $84(60.0)$ & o & $<0.001^{\mathrm{c}}$ \\
\hline Prevalence of Helicobacter pylori infection ${ }^{\mathrm{e}}$ & $75(55.1)$ & $18(69.2)$ & 0.183 \\
\hline Harmful alcohol use on questionnaire ${ }^{b}$ & $21(16.9)$ & o & $0.045^{\mathrm{c}}$ \\
\hline Smoker ${ }^{b}$ & $55(44.0)$ & $9(47 \cdot 4)$ & 0.783 \\
\hline History of gastric cancer & $32(21.3)$ & $26(100)$ & $<0.001^{\mathrm{c}}$ \\
\hline Coronary artery disease & $6(4 \cdot 0)$ & ० & 0.594 \\
\hline Obstructive sleep apnea, diagnosed & $5(3 \cdot 3)$ & o & 1.000 \\
\hline Fatty liver & $18(12.0)$ & o & 0.079 \\
\hline Hypertension & $58(38.7)$ & $8(30.8)$ & 0.443 \\
\hline Diabetes mellitus & $16(10.7)$ & $3(11.5)$ & 1.000 \\
\hline
\end{tabular}

Values are presented as mean \pm SD or number (\%).

${ }^{a}$ Analyzed for 175 patients due to missing values.

${ }^{\mathrm{b}}$ Analyzed for 144 patients due to missing values.

${ }^{\mathrm{c}}$ Statistical significance.

${ }^{\mathrm{d}}$ Analyzed for 166 patients due to missing values.

eAnalyzed for 162 patients due to missing values.

OSA is known to be associated with systemic diseases; however, the association with snoring symptoms during sedative endoscopy has never been studied until now. Snoring under sedation showed a significant association with certain systemic illness as well as a higher risk of OSA on the Korean version of the BQ; however, there was a negative association between snoring during endoscopy with endoscopic findings of chronic atrophic gastritis. Although the numbers of patients with coronary artery disease $(n=6)$ and AGC $(n=9)$ were small, those comorbidities were significantly associated with snoring symptoms after adjusting for other variables. In terms of coronary artery disease, there was a significant difference in the ratio of patients who snored under sedative endoscopy or reported habitual snoring; there were no significant differences in baseline characteristics between patients with and without coronary artery disease (Table 4). Significant differences were found in the prevalence of diabetes mellitus; however, patients with coronary artery disease tended to be older age, male, and weigh more, suggesting that coronary artery disease may be associated with snoring under sedation. These findings need to be validated by larger cohort studies in the future.

This is also the first report on the prevalence of snoring during routine sedative endoscopy in Korea. Among the patients who underwent routine endoscopy, $4.3 \%$ showed snoring symptoms during sedation and we can speculate that this represents the prevalence of snoring symptoms during sedative endoscopy across the Korean population. Because snoring and apnea are generally worse in the supine position and improve in the decubitus position, this prevalence might even be underestimated because patients are in the lateral decubitus position during endoscopy. Nevertheless, this result is similar to that of previous studies [17-19]; Sharara et al. 
Table 4. Comparison of clinical features of patients according to the history of coronary artery disease

\begin{tabular}{|c|c|c|c|}
\hline Variable & $\begin{array}{l}\text { Coronary artery disease } \\
\qquad(\mathrm{n}=6)\end{array}$ & $\begin{array}{c}\text { No history of coronary artery } \\
\text { disease }(n=170)\end{array}$ & $p$ value \\
\hline Age, $\mathrm{yr}^{\mathrm{a}}$ & $65.2 \pm 7.4(63.5[58-76])$ & $61.9 \pm 10.4(62.0[35-87])$ & 0.452 \\
\hline Male sex & $6(100.0)$ & $113(66.5)$ & 0.179 \\
\hline Neck circumference, $\mathrm{cm}^{\mathrm{a}, \mathrm{b}}$ & $37 \cdot 0 \pm 0$ & $37.6 \pm 3.6$ & 0.876 \\
\hline Obesity (body mass index $\geq 25 \mathrm{~kg} / \mathrm{m}^{2}$ ) & $3(50.0)$ & $63(37.1)$ & 0.673 \\
\hline Habitual snoring symptom $\geq 3 /$ week & $4(66.7)$ & $38(22.4)$ & $0.029^{c}$ \\
\hline Patients with snoring during sedative endoscopy & $5(83 \cdot 3)$ & $44(25 \cdot 9)$ & $0.007^{\mathrm{c}}$ \\
\hline High risk group of obstructive sleep apnea & $3(50.0)$ & $52(30.6)$ & 0.378 \\
\hline Gastroesophageal reflux disease ${ }^{\mathrm{d}}$ & $1(20.0)$ & $20(16.8)$ & 1.000 \\
\hline Chronic atrophic gastritis ${ }^{\mathrm{d}}$ & $4(80.0)$ & $80(49 \cdot 7)$ & 0.368 \\
\hline Prevalence of Helicobacter pylori infection ${ }^{\mathrm{e}}$ & $2(40.0)$ & $91(58.0)$ & 0.652 \\
\hline Smoker ${ }^{\mathrm{b}}$ & $1(100)$ & $63(44.1)$ & 0.444 \\
\hline History of gastrectomy & o & $26(15 \cdot 3)$ & 0.594 \\
\hline Advanced gastric cancer & $\mathrm{O}$ & $9(5 \cdot 3)$ & 1.000 \\
\hline Obstructive sleep apnea, diagnosed & $1(16.7)$ & $4(2.4)$ & 0.161 \\
\hline Fatty liver & $1(16.7)$ & $17(10.0)$ & 0.482 \\
\hline Hypertension & $3(50.0)$ & $63(37.1)$ & 0.673 \\
\hline Diabetes mellitus & $4(66.7)$ & $15(8.8)$ & $0.001^{\mathrm{c}}$ \\
\hline
\end{tabular}

Values are presented as mean $\pm \mathrm{SD}$ (median [range]) or number (\%).

${ }^{a}$ Analyzed for 175 patients due to missing values.

${ }^{\mathrm{b}}$ Analyzed for 144 patients due to missing values.

${ }^{\mathrm{c}}$ Statistical significance.

${ }^{\mathrm{d}}$ Analyzed for 166 patients due to missing values.

eAnalyzed for 162 patients due to missing values.

[17] observed that 24 out of 131 patients (18.3\%) snored under conscious sedation and Harvin et al. [18] reported that nine out of the 57 patients (15.8\%) snored. A recent study by Unler et al. [19] reported that only 10 out of 600 patients $(1.7 \%)$ snored. In the present study, we also found that $31.3 \%$ of the study participants were at high risk of OSA based on the Korean version of the BQ; this was quite similar to the results of a previous large, cross-sectional, population-based Korean study, which reported the prevalence of snoring as $31.8 \%$ using the same questionnaires [24].

The credibility and reliability of this study are high, because we recruited patients prospectively and used validated questionnaires administered by specialized investigators. The sensitivity and specificity of the Korean version of the BQ are reported to be relatively high (69\% sensitivity, 83\% specificity) compared with a Western study [15], and the validity and reliability of the AU-
DIT have also been confirmed through numerous studies $[21,22]$.

The association between gastric cancer and snoring symptoms in this study remains unclear yet. There was no difference in age, gender, or BMI between patients with or without a history of AGC, although the rate of snoring was higher in patients with AGC (Supplementary Table 3). The rates of $H$. pylori infection, gastroesophageal reflux disease on the endoscopic exam, hypertension and smoking were not different between patients with and without AGC. However, interpreting these findings in an observational study is difficult. Further studies with larger cohorts are needed to elucidate these findings.

This study has several limitations. First, sedation-induced sleep does not necessarily reflect actual sleep conditions. It is possible that midazolam, a gamma aminobutyric acid-A receptor agonist may have affected the 
snoring symptoms. Genta et al. [25] examined the effects of midazolam sedation on airway critical closing pressure and sleep architecture in men with OSA; however, sleep architecture was found to be similar between natural sleep and midazolam sedation. Besides, midazolam has been widely used for drug-induced sedative endoscopy (nasopharyngoscopy) and is a useful tool for diagnosing OSA. Observation of snoring symptoms during sedative endoscopy is therefore considered significant. Second, polysomnography was not performed in this study; therefore, the diagnosis of OSA in high-risk patients was not confirmed. In a previous study, however, most of the patients who showed snoring during routine sedative endoscopy were diagnosed with OSA by polysomnography [17]. Because we screened the patients who underwent routine endoscopy and verified the patients at risk of OSA by a validated and standardized questionnaire, it is significant to compare the clinical characteristics between patients who snored and those who did not snore. In addition, the patients' comorbidities were determined from the electronic medical records of a single institution; thus, the comorbidities might be underestimated. Also, anatomical aberrations that might affect snoring symptoms were not identified. No correlation was found, however, between a large tongue classified by the modified Mallampati score and obstruction during sleep endoscopy in a previous prospective study [26]. Furthermore, the modified Mallampati score is not usually performed before routine sedative endoscopy; therefore, the score was not considered in this study. Lastly, this study was conducted at a single tertiary hospital with a small number of patients; thus, it may not be possible to apply these results to the general population Future population-based studies will be needed to validate the findings of this study.

Sedative endoscopy, which is generally performed by the gastroenterology department in an elective outpatient setting, is a good opportunity to observe snoring symptoms. Our study demonstrated that patients with snoring symptoms during routine sedative endoscopy might have comorbidities such as coronary artery disease and OSA; this information could prove useful in clinical practice. Based on the results of this study, physicians need to consider patients who snore during sedative endoscopy as potentially having coronary artery disease. The relationship between gastric cancer and snoring during sedative endoscopy, however, still needs to be clarified.

\section{KEY MESSAGE}

1. Among the 1,133 participants, 49 showed snoring symptoms during sedative endoscopy with a prevalence of $4.3 \%$.

2. The risk of obstructive sleep apnea and the prevalence of coronary artery disease and advanced gastric cancer were higher in the snoring group. After adjusting for age, sex, and the number of positive categories on the Berlin Questionnaires, coronary artery disease and advanced gastric cancer were significantly associated with snoring; however, early gastric cancer was not.

3. Our data suggest that patients with snoring symptoms during sedative endoscopy might be at high risk of coronary artery disease and advanced gastric cancer. Our study also suggests that routine sedative endoscopy is a good opportunity to observe patients with persistent snoring symptoms.

\section{Conflict of interest}

No potential conflict of interest relevant to this article was reported.

\section{Acknowledgments}

This work was supported by a grant from the Global Core Research Center (GCRC) of the National Research Foundation (NRF) of Korea funded by the Korean government (MSIP) (No. 2011-0030001).

\section{REFERENCES}

1. Marin JM, Carrizo SJ, Vicente E, Agusti AG. Long-term cardiovascular outcomes in men with obstructive sleep apnoea-hypopnoea with or without treatment with continuous positive airway pressure: an observational study. Lancet 2005;365:1046-1053.

2. Yaggi HK, Concato J, Kernan WN, Lichtman JH, Brass LM, Mohsenin V. Obstructive sleep apnea as a risk factor 
for stroke and death. N Engl J Med 2005;353:2034-2041.

3. Punjabi NM. The epidemiology of adult obstructive sleep apnea. Proc Am Thorac Soc 2008;5:136-143.

4. Young T, Peppard PE, Gottlieb DJ. Epidemiology of obstructive sleep apnea: a population health perspective. Am J Respir Crit Care Med 2002;165:1217-1239.

5. Nieto FJ, Young TB, Lind BK, et al. Association of sleep-disordered breathing, sleep apnea, and hypertension in a large community-based study. Sleep Heart Health Study. JAMA 2000;283:1829-1836.

6. Peppard PE, Young T, Palta M, Skatrud J. Prospective study of the association between sleep-disordered breathing and hypertension. N Engl J Med 2000;342:1378-1384.

7. Young T, Palta M, Dempsey J, Skatrud J, Weber S, Badr $\mathrm{S}$. The occurrence of sleep-disordered breathing among middle-aged adults. N Engl J Med 1993;328:1230-1235.

8. Hiestand DM, Britz P, Goldman M, Phillips B. Prevalence of symptoms and risk of sleep apnea in the US population: results from the national sleep foundation sleep in America 2005 poll. Chest 2006;130:780-786.

9. Sharma SK, Kumpawat S, Banga A, Goel A. Prevalence and risk factors of obstructive sleep apnea syndrome in a population of Delhi, India. Chest 2006;130:149-156.

10. Young T, Evans L, Finn L, Palta M. Estimation of the clinically diagnosed proportion of sleep apnea syndrome in middle-aged men and women. Sleep 1997;20:705-706.

11. Mehta PP, Kochhar G, Kalra S, et al. Can a validated sleep apnea scoring system predict cardiopulmonary events using propofol sedation for routine EGD or colonoscopy? A prospective cohort study. Gastrointest Endosc 2014;79:436-444.

12. Abrishami A, Khajehdehi A, Chung F. A systematic review of screening questionnaires for obstructive sleep apnea. Can J Anaesth 2010;57:423-438.

13. Netzer NC, Stoohs RA, Netzer CM, Clark K, Strohl KP. Using the Berlin Questionnaire to identify patients at risk for the sleep apnea syndrome. Ann Intern Med 1999; 131:485-491.

14. Netzer NC, Hoegel JJ, Loube D, et al. Prevalence of symptoms and risk of sleep apnea in primary care. Chest 2003; 124:1406-1414.

15. Kang K, Park KS, Kim JE, et al. Usefulness of the Berlin Questionnaire to identify patients at high risk for ob- structive sleep apnea: a population-based door-to-door study. Sleep Breath 2013;17:803-810.

16. Bouloukaki I, Komninos ID, Mermigkis C, et al. Translation and validation of Berlin questionnaire in primary health care in Greece. BMC Pulm Med 2013;13:6.

17. Sharara AI, El Zahabi L, Maasri K, et al. Persistent snoring under conscious sedation during colonoscopy is a predictor of obstructive sleep apnea. Gastrointest Endosc 2010;71:1224-1230.

18. Harvin G, Ali E, Raina A, et al. Patients presenting for colonoscopy: a great opportunity to screen for sleep apnea. World J Gastrointest Endosc 2016;8:697-700.

19. Unler GK, Gokturk HS, Dogan R, Kivane T, Karakoca A. Conscious sedation: clues for diagnosing obstructive sleep apnea syndrome. Acta Gastroenterol Belg 2016;79:289-293.

20. World Health Organization. The Asia-Pacific Perspective: Redefining Obesity and Its Treatment. Sydney (AU): Health Communications Australia, 2000.

21. Kim JW, Lee BC, Lee DY, et al. The 5-item Alcohol Use Disorders Identification Test (AUDIT-5): an effective brief screening test for problem drinking, alcohol use disorders and alcohol dependence. Alcohol Alcohol 2013;48:68-73.

22. Piccinelli M, Tessari E, Bortolomasi M, et al. Efficacy of the alcohol use disorders identification test as a screening tool for hazardous alcohol intake and related disorders in primary care: a validity study. BMJ 1997;314:420424 .

23. Kim JS, Oh MK, Park BK, Lee MK, Kim GJ. Screening criteria of alcoholism by alcohol use disorders identification test (AUDIT) in Korea. J Korean Acad Fam Med 1999;20:1152-1159.

24. Kang K, Seo JG, Seo SH, Park KS, Lee HW. Prevalence and related factors for high-risk of obstructive sleep apnea in a large Korean population: results of a questionnaire-based study. J Clin Neurol 2014;10:42-49.

25. Genta PR, Eckert DJ, Gregorio MG, et al. Critical closing pressure during midazolam-induced sleep. J Appl Physiol (1985) 2011;111:1315-1322.

26. den Herder C, van Tinteren H, de Vries N. Sleep endoscopy versus modified Mallampati score in sleep apnea and snoring. Laryngoscope 2005;115:735-739. 


\section{Supplementary Table 1. The Korean version of the Berlin Questionnaire}

\begin{tabular}{|c|c|}
\hline Categories & Item content \\
\hline $\begin{array}{l}\text { Category } 1 . \\
\text { Habitual snoring }\end{array}$ & $\begin{array}{l}\text { 1. Do you snore? } \\
\text { a. Yes } \\
\text { b. No } \\
\text { c. Do not know } \\
\text { 2. If yes, loudness of your snoring is: } \\
\text { a. As loud as breathing } \\
\text { b. As loud as talking } \\
\text { c. Louder than talking } \\
\text { 3. How often do you snore? } \\
\text { a. Almost every day } \\
\text { b. 3-4 times per week } \\
\text { c. 1-2 times per week } \\
\text { d. 1-2 times per month } \\
\text { e. Rarely or almost never } \\
\text { 4. Has your snoring ever bothered other people? } \\
\text { a. Yes } \\
\text { b. No } \\
\text { c. Do not know } \\
\text { 5. Has anyone noticed that you stop breathing during your sleep? } \\
\text { a. Almost every day } \\
\text { b.3-4 times per week } \\
\text { c. 1-2 times per week } \\
\text { d. 1-2 times per month } \\
\text { e. Rarely or almost never }\end{array}$ \\
\hline $\begin{array}{l}\text { Category } 2 . \\
\text { Wake-time sleepiness or tiredness }\end{array}$ & $\begin{array}{l}\text { 6. How often do you feel tired or fatigued after sleeping? } \\
\text { a. Almost every day } \\
\text { b. 3-4 times per week } \\
\text { c. 1-2 times per week } \\
\text { d. 1-2 times per month } \\
\text { e. Rarely or almost never } \\
\text { 7. During your waking time, do you feel tired, fatigued or not up to par? } \\
\text { a. Almost every day } \\
\text { b. 3-4 times per week } \\
\text { c. 1-2 times per week } \\
\text { d. 1-2 times per month } \\
\text { e. Rarely or almost never } \\
\text { 8. Have you ever nodded off or fallen asleep while driving a vehicle? } \\
\text { a. Yes } \\
\text { b. No } \\
\text { 9. If yes, how often does this occur? } \\
\text { a. Almost every day } \\
\text { b. 3-4 times per week } \\
\text { c. 1-2 times per week } \\
\text { d. 1-2 times per month } \\
\text { e. Rarely or almost never }\end{array}$ \\
\hline $\begin{array}{l}\text { Category } 3 . \\
\text { The presence of hypertension or obesity }\end{array}$ & $\begin{array}{l}\text { 10. Do you have high blood pressure? } \\
\text { a. Yes } \\
\text { b. No } \\
\text { c. Do not know }\end{array}$ \\
\hline
\end{tabular}


Supplementary Table 2. The Alcohol Use Disorders Identification Test (AUDIT)

\begin{tabular}{|c|c|}
\hline Domains & Item content \\
\hline Hazardous alcohol use & $\begin{array}{l}\text { 1. How often do you have a drink containing alcohol? } \\
\text { o. Never } \\
\text { 1. Monthly or less } \\
\text { 2. } 2-4 \text { times a month } \\
\text { 3. } 2-3 \text { times a week } \\
\text { 4. } 4 \text { or more times a week } \\
\text { 2. How many drinks containing alcohol do you have on a typical day when you are drinking? } \\
\text { 0. } 1 \text { or } 2 \\
\text { 1.3 or } 4 \\
\text { 2. } 5 \text { or } 6 \\
\text { 3. } 7 \text { to } 9 \\
\text { 4. } 10 \text { or more } \\
\text { 3. How often do you have six or more drinks on one occasion? } \\
\text { o. Never } \\
\text { 1. Less than monthly } \\
\text { 2. Monthly } \\
\text { 3. Weekly } \\
\text { 4. Daily or almost daily }\end{array}$ \\
\hline Dependence symptoms & $\begin{array}{l}\text { 4. How often during the last year have you found that you were not able to stop drinking once you } \\
\text { had started? } \\
\text { o. Never } \\
\text { 1. Less than monthly } \\
\text { 2. Monthly } \\
\text { 3. Weekly } \\
\text { 4. Daily or almost daily } \\
\text { 5. How often during the last year have you failed to do what was normally expected of you because } \\
\text { of drinking? } \\
\text { o. Never } \\
\text { 1. Less than monthly } \\
\text { 2. Monthly } \\
\text { 3. Weekly } \\
\text { 4. Daily or almost daily } \\
\text { 6. How often during the last year have you needed a first drink in the morning to get yourself go- } \\
\text { ing after a heavy drinking session? } \\
\text { o. Never } \\
\text { 1. Less than monthly } \\
\text { 2. Monthly } \\
\text { 3. Weekly } \\
\text { 4. Daily or almost daily }\end{array}$ \\
\hline
\end{tabular}


Supplementary Table 2. Continued

Domains
Harmful alcohol use $\quad \begin{aligned} & \text { 7. How often during the last year have you had a feeling of guilt or remorse after drinking? } \\ & \text { o. Never } \\ & \text { 1. Less than monthly } \\ & \text { 2. Monthly } \\ & \text { 3. Weekly } \\ & \text { 4. Daily or almost daily } \\ & \text { 8. How often during the last year have you been unable to remember what happened the night } \\ & \text { before because of your drinking? } \\ & \text { o. Never } \\ & \text { 1. Less than monthly } \\ & \text { 2. Monthly } \\ & \text { 3. Weekly } \\ & \text { 4. Daily or almost daily } \\ & \text { 9. Have you or someone else been injured because of your drinking? } \\ & \text { o. Never } \\ & \text { 2. Yes, but not in the last year } \\ & \text { 4. Yes, during the last year } \\ & \text { 10. Has a relative, friend, doctor, or other health care worker been concerned about your drinking } \\ & \text { or suggested you cut down? } \\ & \text { o. Never } \\ & \text { 2. Yes, but not in the last year } \\ & \text { 4. Yes, during the last year }\end{aligned}$




\section{KJIM}

Supplementary Table 3. Comparison of clinical features of patients according to the history of gastric cancer

\begin{tabular}{|c|c|c|c|c|c|}
\hline \multirow[b]{2}{*}{ Variable } & \multirow{2}{*}{$\begin{array}{l}\text { Advanced gastric } \\
\text { cancer }(\mathrm{n}=9)\end{array}$} & \multicolumn{4}{|c|}{ No history of advanced gastric cancer $(n=168)$} \\
\hline & & $\begin{array}{c}\text { Early gastric } \\
\text { cancer }(\mathrm{n}=49)\end{array}$ & $p$ value $^{\mathrm{a}}$ & $\begin{array}{c}\text { No history of } \\
\text { gastric cancer }(n=118)\end{array}$ & $p$ value ${ }^{\mathrm{b}}$ \\
\hline Age, $\mathrm{yr}^{\mathrm{c}}$ & $64.0 \pm 7.5$ & $63.0 \pm 10.1$ & 0.787 & $61.5 \pm 10.6$ & 0.487 \\
\hline Male sex & $8(88.9)$ & $36(73 \cdot 5)$ & 0.431 & $75(63.6)$ & 0.161 \\
\hline Height, $\mathrm{cm}^{\mathrm{c}}$ & $165.0 \pm 5.4$ & $163.6 \pm 7.1$ & 0.568 & $165.1 \pm 8.5$ & 0.963 \\
\hline Body weight, $\mathrm{kg}^{\mathrm{c}}$ & $59.7 \pm 5.2$ & $64.1 \pm 10.3$ & 0.069 & $66.6 \pm 13.8$ & $0.005^{\mathrm{d}}$ \\
\hline Neck circumference, $\mathrm{cm}^{\mathrm{c}, \mathrm{e}}$ & $36.4 \pm 4.4$ & $37 \cdot 5 \pm 3.0$ & 0.448 & $37 \cdot 7 \pm 3.8$ & 0.440 \\
\hline Obesity (body mass index $\geq 25 \mathrm{~kg} / \mathrm{m}^{2}$ ) & 0 & $15(30.6)$ & 0.094 & $51(43.2)$ & $0.011^{d}$ \\
\hline Habitual snoring symptom $\geq 3 /$ week & $4(44 \cdot 4)$ & $6(12.2)$ & $0.039^{\mathrm{d}}$ & $32(27.1)$ & 0.271 \\
\hline Snoring during sedative endoscopy & $6(66.7)$ & $7(14 \cdot 3)$ & $0.002^{\mathrm{d}}$ & $36(30.5)$ & 0.058 \\
\hline High risk group of obstructive sleep apnea & $3(33 \cdot 3)$ & $12(24 \cdot 5)$ & 0.388 & $40(33.9)$ & 1.000 \\
\hline Gastroesophageal reflux disease $\mathrm{f}^{\mathrm{f}}$ & $1(11.1)$ & $6(12.2)$ & 1.000 & $21(19.4)$ & 1.000 \\
\hline Chronic atrophic gastritis on endoscopy ${ }^{f}$ & o & $27(55 \cdot 1)$ & $0.002^{\mathrm{d}}$ & $57(52.8)$ & $0.003^{\mathrm{d}}$ \\
\hline Prevalence of Helicobacter pylori infection ${ }^{g}$ & $7(77.8)$ & $33(67 \cdot 3)$ & 0.706 & $86(56.6)$ & 0.304 \\
\hline Harmful alcohol use on questionnaire ${ }^{\mathrm{e}}$ & o & $3(6.8)$ & 1.000 & $18(20.1)$ & 0.588 \\
\hline Smoker ${ }^{\mathrm{e}}$ & $2(33 \cdot 3)$ & $25(58.1)$ & 0.245 & $37(31.4)$ & 1.000 \\
\hline Coronary artery disease & O & o & - & $6(5 \cdot 1)$ & 1.000 \\
\hline Cerebral ischemia & $1(11.1)$ & $2(4.1)$ & 0.403 & $5(4.2)$ & 0.363 \\
\hline Obstructive sleep apnea, diagnosed & o & o & - & $5(4.2)$ & 1.000 \\
\hline Fatty liver & o & 0 & - & $18(15 \cdot 3)$ & 0.357 \\
\hline Hypertension & $4(44 \cdot 4)$ & $16(32.7)$ & 0.559 & $46(39.0)$ & 0.738 \\
\hline Diabetes mellitus & $1(11.1)$ & $4(8.2)$ & 1.000 & $14(11.9)$ & 1.000 \\
\hline
\end{tabular}

Values are presented as mean \pm SD or number (\%).

${ }^{a} p$ value was analysed between group of advanced gastric cancer and group of early gastric cancer.

${ }^{b} p$ value was analysed between group of advanced gastric cancer and group without history of gastric cancer.

${ }^{\mathrm{c}}$ Analyzed for 175 patients due to missing values.

${ }^{\mathrm{d}}$ Values indicate statistical significance.

${ }^{\mathrm{e}}$ Analyzed for 144 patients due to missing values.

${ }^{\mathrm{f}}$ Analyzed for 166 patients due to missing values.

${ }^{g}$ Analyzed for 162 patients due to missing values. 